


\section{ENOUGH IS ENOUGH!}

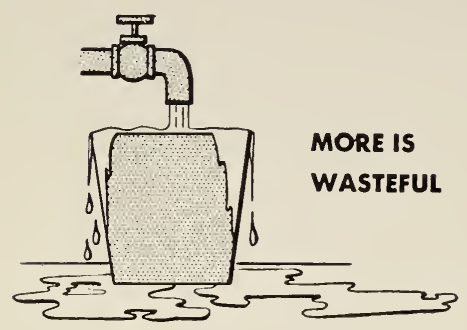

To keep the soil supplied with readily available moisture AT ALL TIMES.

Nothing is gained by irrigating often enough to keep the soil moisture at a high level.

But if the soil is allowed to become dry for a considerable time, this may result in harmful effects on

Tree size

Yield

Fruit size

Fruit quality.

\section{The main purpose of cultivation:}

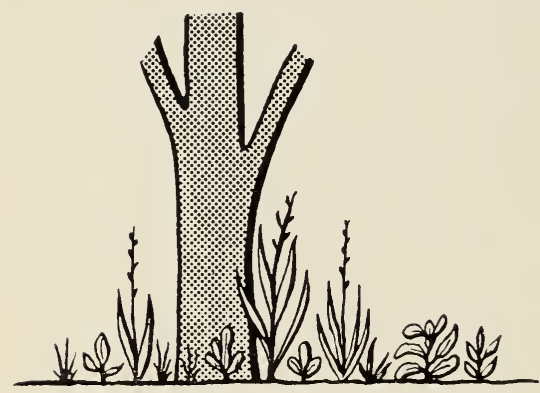

To remove weed competition. Cultivation itself does not conserve moisture.

This circular presents the principles on which good irrigation and cultivation practices in orchards are founded. The same principles also apply to other crops. The information of this publication is based on research conducted in California.

This circular replaces Extension Circular 50, originally issued 1930

\section{The Authors:}

F. J. Veihmeyer is Professor of Irrigation, Emeritus, and Irrigation Engineer, Emeritus, in the Experiment Station, Davis. A. H. Hendrickson is Pomologist, Emeritus, in the Experiment Station, Davis. 


\section{Research has shown that:}

often contrary to widespread belief, deciduous fruit trees need readily available moisture all year around; but no additional benefits are gained by adding more water to that already available.

Beneficial results of good irrigation practices, such as increased yields, are cumulative and require many years to appear.

Harmful results of poor irrigation practices, such as decreased fruit size, may show up immediately when trees are not supplied with readily available moisture.

Large trees need no more water than small ones, as long as the area shaded by the leaves is the same.

Cover crops in the orchard do not conserve soil moisture.

Withholding irrigation does not make the trees send down their roots more deeply into the soil.

\section{Contents}

IRRIGATION OF ORCHARDS

Water in soils

Measuring soil moisture .

Methods of irrigation

Use of water by trees

Tree responses to soil-moisture conditions . . . . . . . . . . . . . 14

Irrigation during the growing season . . . . . . . . . . . . . 20

Seasonal irrigation . . . . . . . . . . . . . . . . . . 23

Influence of irrigation on root distribution . . . . . . . . . . . . . . 24

CULTIVATION OF ORCHARDS . . . . . . . . . . . . . . . . . . 25 


\section{IRRIGATION OF ORCHARDS}

Soil moisture in this circular is discussed from the standpoint the grower is most interested in-the availability of water to the trees. For a clearer understanding of the terms used in this publication the most important ones are defined and briefly discussed on pages 4 to 10 under the line.

\section{WATER IN SOILS}

How water is stored in soil. Soil is a porous material composed of particles of many different sizes touching each other, but leaving space in between. This space is called pore space and is the place where water in soil is stored.

Soil is a reservoir for water. The soil in which tree roots are growing is like a reservoir containing various amounts of water at different times a year.
In California, the soil containing these roots is ordinarily filled to its field capacity at the beginning of the growing season. In unirrigated mature orchards where drainage is unrestricted, the readily available moisture in the soil occupied by the roots is usually exhausted before the end of the growing season. The trees then remain wilted until fall rains renew the water supply. In other words, the trees use all the readily available water and then exist as best they can. This situation can only be remedied by irrigation.

How soils are wetted. After an irrigation, the soil throughout the portion wetted is at uniform moisture content. The water moves downward mostly by gravity; capillarity cannot be depended upon to distribute moisture uni(Continued on page 6)

\section{$\begin{array}{lllllllllllllll}\text { G } & \text { L } & \text { O } & \text { S } & \text { S } & \text { A } & \text { R } & \text { Y } & \text { O } & \text { F } & \text { T } & \text { E } & \text { R } & \text { M } & \text { S }\end{array}$}

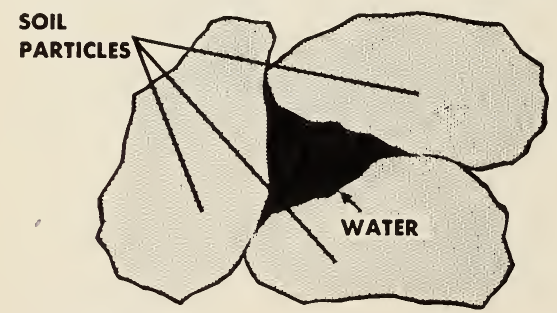

SATURATION

Water fills pore space between soil particles almost completely.

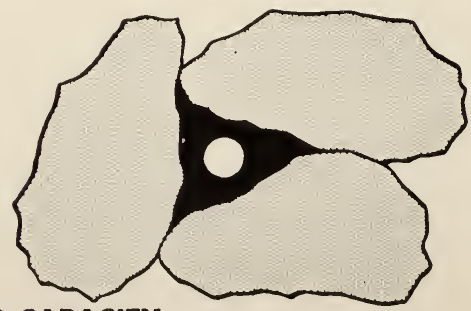

FIELD CAPACITY

Water remaining after drainage exists in form of wedges between particles.
Saturation of the soil is the condition in which the pore spaces are filled almost completely with water. A soil is saturated or nearly so for a short time after water is applied until drainage takes place.

Field capacity is all the water a soil will hold after drainage has taken place. During drainage, water moves downward and, to a lesser extent, sideways, by gravity. A limited amount of water is also capable of moving by capillarity, but you cannot depend on it for moving water in the soil.

At field capacity, each soil particle is completely surrounded by water but most of it exists in the form of wedges between the soil particles at their points of contact. It is from these wedges that plants get most of their water. 


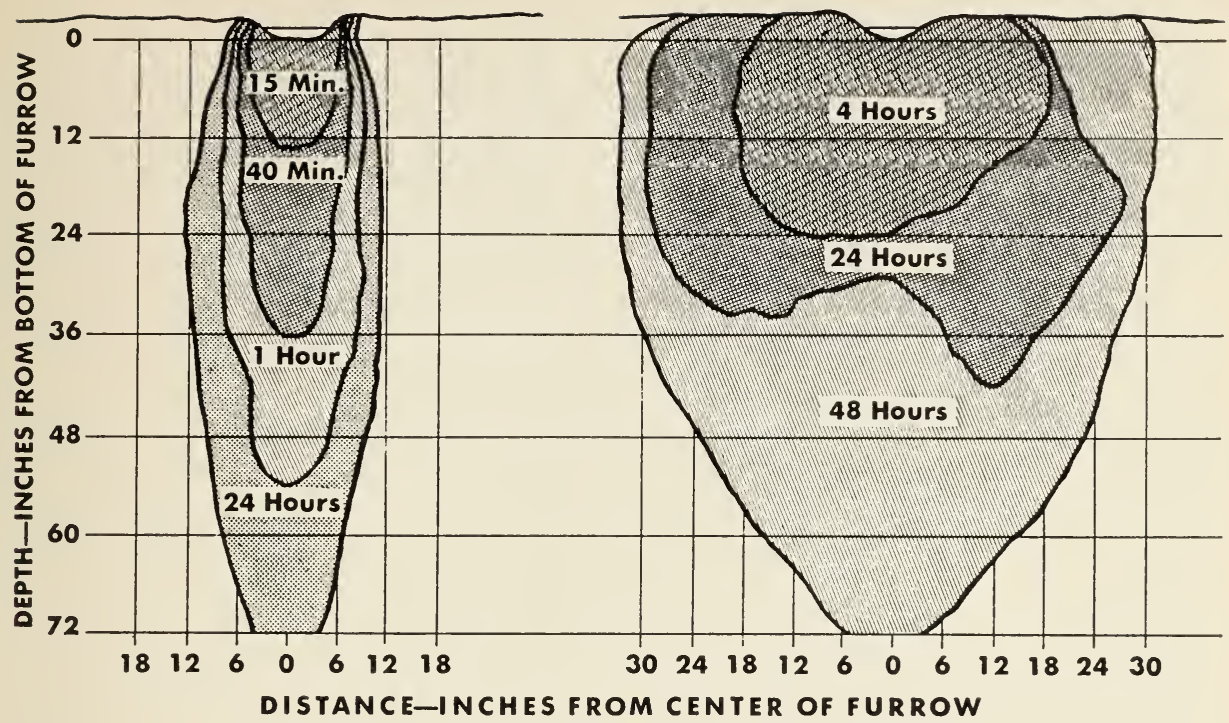

A light irrigation simply wets a shallower depth to its field capacity than heavy irrigation does. Soils cannot be partially wetted. They must be completely wetted or not at all.

\section{$\begin{array}{lllllllllllllllllll}\text { U } & \mathbf{S} & \mathbf{E} & \mathbf{D} & \mathrm{I} & \mathbf{N} & \mathrm{T} & \mathbf{H} & \mathbf{I} & \mathbf{S} & \mathbf{C} & \mathbf{I} & \mathbf{R} & \mathbf{C} & \mathbf{U} & \mathbf{L} & \mathbf{A} & \mathbf{R}\end{array}$}

When irrigation water is applied to a soil, that soil is moistened to its field capacity to a definite depth, which depends on the dryness of the soil and the amount of water used.

The moistened portion of a drained soil of uniform texture and structure reaches its field capacity two or three days after a rain or irrigation. This time span is increased if there are layers of soil which hinder the movement of water.

The field capacity is the approximate starting point from which trees begin to use water from the soil in their normal functions of growth and fruiting. They may, however, use some water during irrigation before the field capacity is reached.

Field capacity is influenced by:

Soil texture-the size of the soil par. ticles, indicating coarseness or fineness of the soil. In general, the fine-textured soils such as clays and loams hold more water at field capacity than the sands. This is so because most of the particles in fine-textured soils are very small, therefore have more particles in a unit volume of soil, and consequently have more water-holding wedges. The amount of water may be greatly influenced by the extremely small particles (colloids) in the soil. Adding organic matter will only slightly increase the field capacity, and usually only in the surface layer. The amount of water in the soil at saturation will not vary much with texture of soils from the same rock material.

Soil structure-the pattern in which soil particles are arranged. It may influence the water penetration of the soil.

Uniformity of soil texture and struc- 
formly. Hence, a light irrigation simply wets a shallower depth to its field capacity than a heavy one does; it does not bring about a moisture condition less than the field capacity. Or, simply stated, soils cannot be partially wetted; they must be completely wetted or not at all (see the drawing on page 5 ).

The field capacity may be exceeded, of course, in undrained soils. On the other hand, portions of the soil will remain dry where furrows are too far apart, as lateral movement caused by capillarity is very limited. A plow sole or decided differences in soil texture or structure will increase the lateral movement.

\section{MEASURING SOIL MOISTURE}

When is irrigation necessary? This question may be answered by measuring the amount of moisture in the soil. However, not all the water remaining in the soil at a given time can be used by the trees. (See discussion of readily available moisture on page 8 below the line).

You may measure soil moisture by several methods, but the quick and easy ones are not always the most reliable.

Soil sampling. The best method of measuring soil moisture is by taking soil samples from various depths and locations, with a soil tube or auger, drying the samples in an oven, and calculating the water content. This method is accurate, gives a true value for the undisturbed core of soil, and makes it possible to secure an adequate number of samples. It has the disadvantage of needing considerable equipment and requiring two days or more for the drying, weighing, and calculating.

In California, the growing season is rainless or nearly so, and the climatic conditions affecting plants are similar year after year. After sampling your soil for several years you will find that, if the winter rainfall has been adequate and

\section{Glossary continued}

ture. For instance, if a fine-textured soil (clay) overlies a coarser soil (sand or gravel), the zone immediately above the clay will have a higher field capacity than the clay would have if it were uniform throughout.

Soil depth. A shallow soil holds more water in a unit depth at field capacity than a deep soil of the same kind; but this difference is not marked in soils deeper than about 2 leet.

Presence of water table. The moisture content just above the water table is greater than that which this soil would have if it were drained. The distance above the water table affected this way is greater in clays than in sands. However, the amount of water held in the soil occupied by the roots is increased measurably only by shallow water tables, and not by deep ones.
Moisture equivalent is a common laboratory method of measuring soilmoisture conditions. It helps estimate the amount of water the soil will hold shortly after a rain or irrigation. It would be preferable to measure field capacity directly, but this is not always practical. The moisture equivalent measure agrees closely with the field capacity in most fine-textured soils, but usually is lower than that of the sands.

"Wilting coefficient" (the moisture equivalent divided by the factor 1.84) has been assumed as the point above which plants would not wilt. However, this relationship does not hold for all soils. There are enough exceptions to make its use doubtful.

Before you accept recommendations for irrigation practices based on moisture equivalent alone, be aware of the limitations of the methods and of the fact that it cannot be used to measure 
irrigations during the growing season have penetrated to a uniform depth each time, the dates when you need further irrigations will fall at about the same time each year. For example, a mature deciduous fruit orchard in the Sacramento Valley on fine-textured soils with a depth of at least six feet will not need irrigation until the latter part of June in a year of normal rainfall. If the soil is wet to a depth of six feet, a second irrigation will not be needed until after mid-August.

Instruments with immediate readings. Various devices exist to measure soil moisture without the drudgery of soil sampling. In general, these instruments have the advantage of immediate readings. But they also have serious disadvantages. Some are not always reliable at low moisture contents, others are not accurate at high moisture contents. Their calibrations may not remain correct after these instruments have been in place for some time. Finally, there are usually not enough of these instruments to give an adequate number of readings, and they must of necessity be placed in holes where the soil has been disturbed, and the soil may not have been repacked to the same density of the undisturbed soil. Roots must penetrate into the region of disturbed soil before the reading of the instrument becomes meaningful. To take a quantitative measurement of soil moisture content, these devices must be calibrated by testing them in soil of known moisture content. This requires that the tests be made on all the kinds of soils in the orchard. Nevertheless, these instruments will show you that changes in soil moisture are taking place, and may cause you to pay more attention to your soil moisture conditions.

The Atmometer is an inexpensive device used to estimate the extraction of water from the soil (and thus the necessity for the next irrigation) by measuring accurately the amount of water available for plants.

Permanent wilting percentage (PWP) is the moisture content of the soil below which the trees cannot readily obtain water; plants will wilt, and will not recover unless water is applied to the soil. In a given soil all plants will wilt permanently at the same moisture content.

Wilting or drooping of leaves is the most common symptom that the PWP has been reached. Some plants will not wilt but show other signs such as decreased plant or fruit growth, or change of color of leaves.

Because it is difficult to obtain precise results in soil sampling and to determine exactly when a tree is wilted, this circular uses the term PWP as a narrow range of soil-moisture contents within which wilting takes place. The PWP covers a range of about 1 per cent

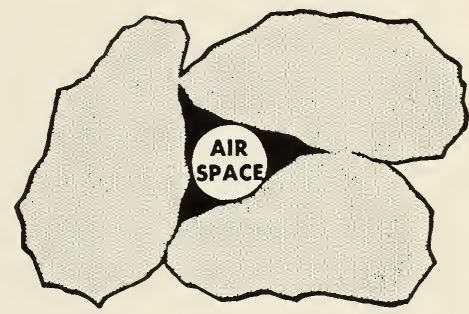

P. W. P.

Water between particles is reduced to a point that it becomes unavailable to plants.

of soil moisture in fine-textured soils and about $1 / 2$ per cent in sands.

Drooping of leaves, usually in the late afternoon, is a sign that soil moisture has been reduced close to the PWP. If this wilted condition is still noticeable when transpiration begins the following morning, for most soils this means that the PWP has been reached in that part of the soil which 
the water evaporated from the atmometers. The instrument consists of two water-filled hollow-porous porcelain spheres with thin walls, one white, and the other black. The white sphere reflects most of the solar energy falling on it, while the black one absorbs most of it. This makes the difference in evaporation between the black and white sphere a good measure of insolation (sun energy). The pair of atmometers act like a pyrheliometer.

Experiments have shown that extraction of moisture from the soil by the trees is correlated with the difference in evaporation from the black and white atmometers. Hence, when you know the relationship between the extraction of soil moisture and evaporation of water from the atmometers, you can calculate with a fair degree of accuracy when the next irrigation is necessary. Many fruitgrowing counties of California are equipped with atmometers, and records of evaporation from them can be obtained from the Farm Advisors.

\section{METHODS OF IRRIGATION}

Your method of irrigating orchards will depend on the size of stream you have available, on topography, soil, climate, and the general tendency to follow the practice prevalent in your locality.

Furrows can be used if the slope of your land and the size of your stream are such that they will not cause erosion. Space the furrows closely enough together so that the wetted areas meet and the water is kept in the furrows until it has penetrated to the desired depth. Regulate the length of the furrow so that the difference in penetration between the upper and lower ends is not great. Also regulate the size of the irrigation stream in accordance with rate of water intake by the soil.

\section{Glossary continued}

is filled by the major portion of the root system; the normal activities of the tree are then limited.

Readily available moisture is the moisture above the PWP. Soil moisture is also present below the PWP but is held so tightly by soil particles that plant roots cannot absorb it rapidly enough to prevent wilting. The water in the soil above the PWP, throughout the entire range of moisture contents up to field capacity, can be used by plants with equal easeit is readily available moisture.

The simplest way to determine the amount of readily available moisture in a soil at known field capacity is by growing a plant on it and finding the PWP.

The field capacity of clay soils is greater than that of sandy soils, but some sandy soils contain more readily available moisture than some clays. The readily available water varies from about one-quarter to three-quarters of the moisture equivalent. These differences do not depend on the textural grade (that is, whether it is clay, loam, or sand).

The amount of readily available water is like the water that can be drawn from a faucet on the side of a barrel filled with water. The amount of water in the barrel is the field capacity. The water above the faucet may be drawn off and is the readily available moisture. The water below the faucet is present but cannot be drawn off. The lower the faucet, the more water can be drawn off. Some soils are like barrels with low faucets; others like those with high faucets. 


\section{CONTOUR FURROWS}

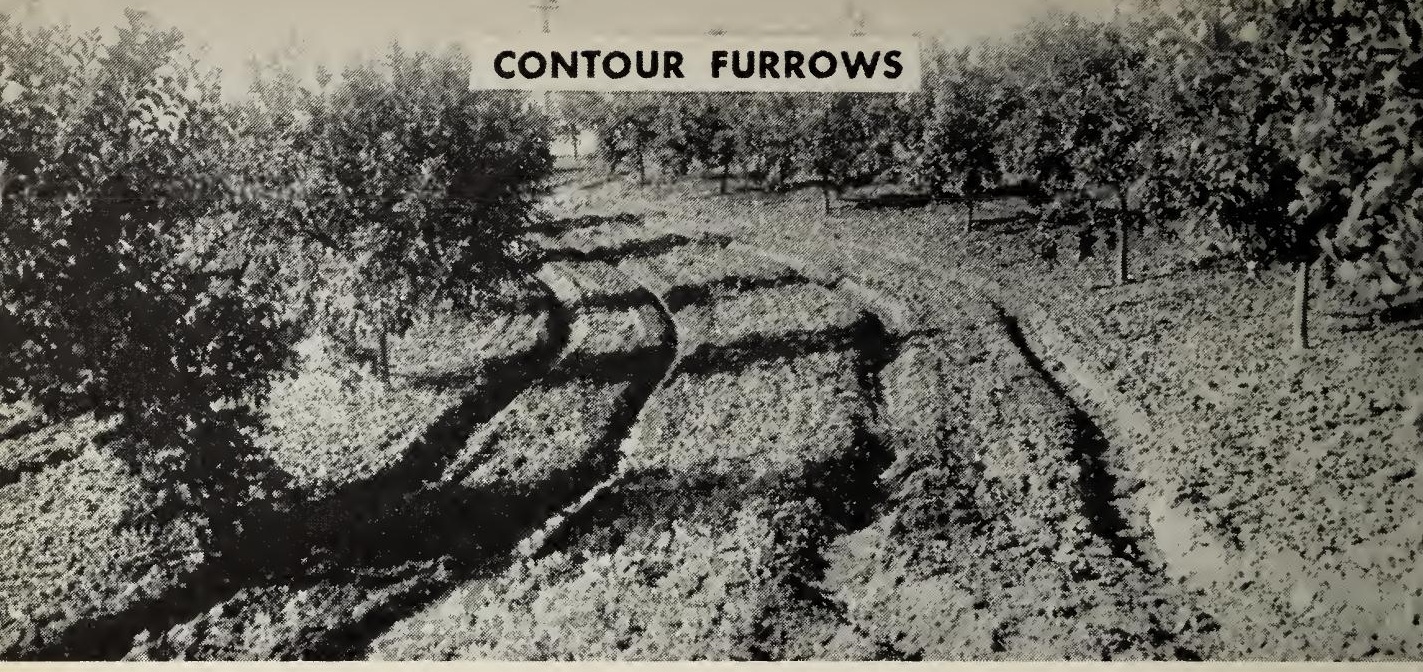

Graded contour furrows are sometimes used on steep slopes, i.e., on land with slopes up to 25 per cent, the grades of the furrows being .5 to 1.5 per cent, depending on soil type.

\section{Glossary concluded}

This analogy needs to be modified, however. Some of the water in the soil below the PWP can be used by plants, although the rate of use is drastically reduced.

Field capacity and PWP, for all practical purposes, are constant for a given soil. Additions of organic or inorganic fertilizers, in amounts usually applied in orchards, will not change these soil properties enough to be of practical importance. For example: an increase in the field capacity by adding manure also increases the PWP; hence, the readily available moisture remains unchanged for all practical purposes.

Cultivation with heavy machinery or traffic through the orchard, especially on wet soil, may result in soil compaction. In some soils a slight increase in density of the soil will prevent the roots from penetrating into it. Field capacity and PWP determinations under these conditions may be misleading if they are made on fragmented samples.

Optimum moisture, a "best" soil moisture content for plant growth, is a false idea. It usually is expressed by a moisture percentage from the field capacity. However, there is no one percentage of readily available moisture at which plants grow better than at another. Even if there were such a theoretical optimum moisture content of a soil, it could not be maintained, and therefore would be of no practical importance. All attempts to maintain any soil-moisture content lower than field capacity have failed because movement of moisture in the soil by capillarity is too slow to bring about a uniform distribution in the soil.

Wet soil is soil containing readily available moisture. It is not necessarily a wet-looking soil, nor a soil which, when squeezed, contains water.

Dry soil, accordingly, is soil from which plants cannot readily obtain water, regardless of whether the water is present or not. 


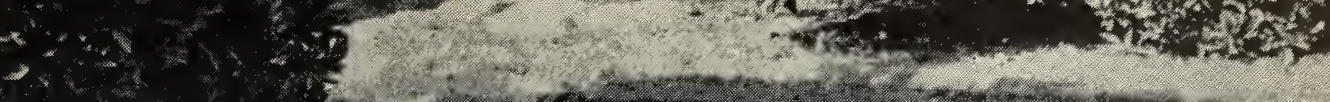

(n)

$+x^{2}, 3$

.

\section{ZIGZAG FURROWS}

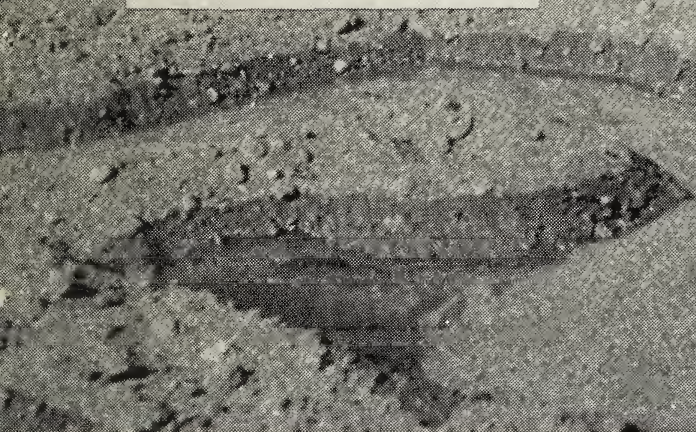

Zigzag or check-back furrows may be used to reduce the grade of the furrows or to insure wetting the soil in the tree rows.

Rectangular checks, either for single tree or multiple-tree basins, are adapted to land that can be leveled within .2 foot per 100 feet. You may enclose one or more trees in a basin. For a large number of trees use long rectangular checks.

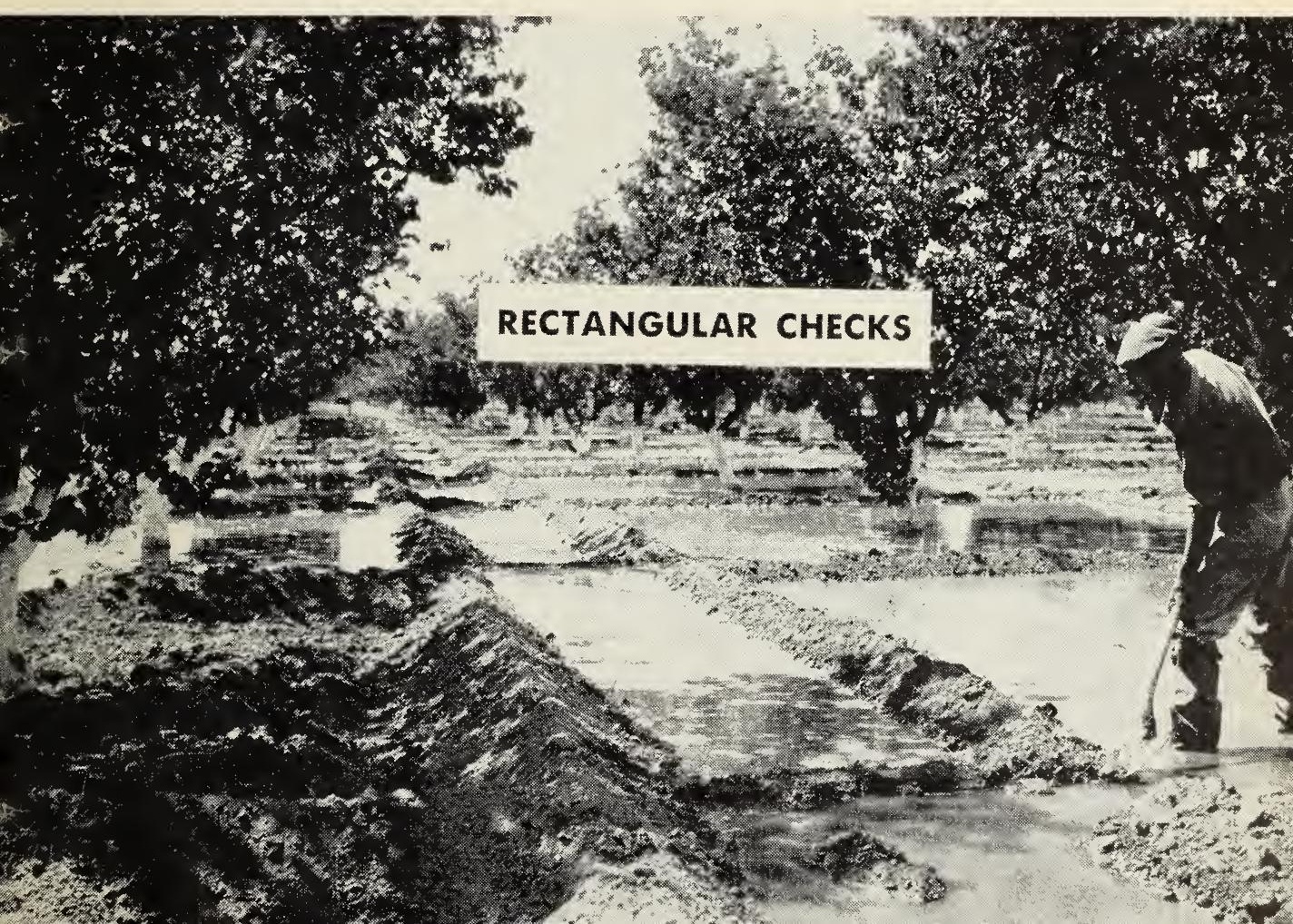


Sprinklers can be used under a variety of conditions, and are adapted to rolling or steep lands. Their advantage for irrigating orchards is that they need no leveling, and that they can make use of small streams of water. Usually sprinkling results in an approximate uniform wetting of the soil.

The disadvantages of sprinkling are:

It requires high capital investment and maintenance costs.

The amount of water that usually can be applied at one setting of the pipelines is limited. The depth of application for a given time, which in orchards is generally limited by two moves of the pipelines in 24 hours, is controlled by the rate at which the soil will take water, and the discharge rate of the nozzles. Lengthening of time of setting, of course, means increasing the amount of equipment to sprinkle the entire area in a given time, and adding to the cost of the pipe and sprinklers.

The operation of sprinklers is inflexible after the original design of the system is adopted. Low hanging branches of trees may interfere with the spray from the sprinklers and cause uneven distribution of water.

\section{USE OF WATER BY TREES}

Water taken from the soil by trees is almost entirely given off as water vapor through the leaves. This "transpiration" is like evaporation from a piece of wet paper; it may be controlled to some extent by internal conditions within the plant.

\section{External factors influencing tran-} spiration, other than soil moisture, are sunlight, temperature, humidity, and wind (drawing below). Of those, the amount and quality of sunlight is probably the most important. High temperatures are usually accompanied by low humidities. This tends to increase transpiration. Transpiration may be less on a calm than on a windy day, but does not increase in direct proportion to wind velocity. The effect sometimes noticed on leaves after a period of strong winds is probably due to the combination of low relative humidity, high temperatures, intense sunlight, and mechanical injury.

Size of trees does not influence the amount of water used by the orchard. If the ground area shaded by the leaves of the trees is the same, the use of water is the same regardless of whether the

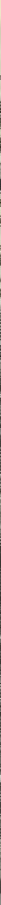


THESE FACTORS INFLUENCE

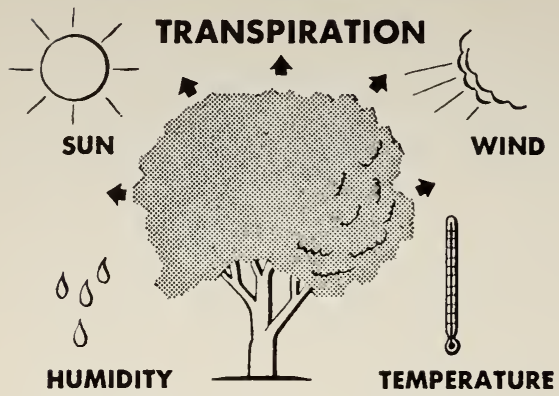

trees are large or small. The shading or ground coverage is determined by the spacing of the trees and their growth habit. What counts is not the number of leaves on the trees but rather the number of leaves directly exposed to sunlight. Our experiments show that the use of water from large walnut trees is almost the same as that from low-growing plants such as alfalfa, if the ground is fully covered by the foliage of the plants.

Presence or absence of fruit does not materially influence the amount of water used by the trees.

Time of year. Transpiration by deciduous trees is confined almost entirely to that part of the year when leaves are present, although some water is used during the leafless period. Our experiments with prunes, peaches, and apricots indicate that the use of water depends upon the ground coverage of the trees, and not upon the particular kind. However, this may not apply to trees differing from deciduous trees as widely as the olive and orange, when the total seasonal use is considered.

Evergreen trees use water throughout the year, but the amounts used in the winter usually are much less than in the summer.

Use of water above the PWP. The extraction of water from the soil by trees is not affected by soil moisture until it is reduced to the PWP in that part of the soil that is reached by the roots. The use of water is influenced by the factors mentioned before, but their effect is much more marked when the moisture is above the PWP.

At the PWP or below, trees use water very slowly even if climatic conditions are favorable for transpiration. The rate of use varies with the surrounding conditions, and may not be the same during each hour of the day. Experiments in deciduous orchards under fairly uniform climatic conditions show, however, that the rate of moisture use is substantially constant day by day until the soil moisture is reduced to about the PWP. Of course, changes in evaporation conditions during the day and from day to day, such as between a foggy and a bright day, will cause corresponding changes in transpiration rates. Transpiration is highly correlated with solar energy.

\section{TREE RESPONSES TO SOIL-MOISTURE CONDITIONS}

Fruit growth is retarded, and other symptoms appear, when the soil contain ing most of the roots has been reduced to the PWP. The degree of injury depends on the length of time the soil remains in this condition.

Irrigation experiments in California deciduous orchards yielded many results and observations on the response of fruit trees to various soil-moisture conditions, particularly those in which trees were allowed to remain permanently wilted for relatively long periods.

Tree responses to irrigation practices fall into two general classes:

Short-term results: the response is immediate and takes effect the same season. In general, immediate results are usually harmful, and follow changes in practice involving neglect or ceasing to irrigate, especially during certain critical periods. Decreased size in many fruits, delay in maturity of pears, and a lowered percentage of well-filled shells in walnuts are some of the results that immediately 
follow a failure to keep the trees supplied with readily available moisture.

Long-term results: the response to a given irrigation program appears slowly and is sometimes apparent only after several years. In general, the beneficial results are those requiring several years of good irrigation practice. Increases in yield, for instance, are as a rule the reward for the long-continued practice of keeping the trees supplied with readily available water throughout the year.

Briefly, the initiation of good irrigation practice does not bring about the beneficial results as if by magic, but lack of moisture may cause serious loss the same season.

\section{Effect of Irrigation on Tree Size}

One of the most noticeable responses of peach and prune trees was the slow but comparatively steady gain in size, as measured by the cross-section areas of tree trunks, of the irrigated over the unirrigated trees.

At the beginning of the experiment, the plots were divided into treatments in such a way that the average sizes of trees and the average yields were about equal.

After two years, the trees in the irrigated plots showed evidence of growing faster than those in the unirrigated plots. As the experiment progressed, the unirrigated trees and those in the intermediate plots in which the soil-moisture was reduced to the PWP for varying periods, continued to grow more slowly, until the irrigated trees were distinctly the largest, with the intermediate plots in second place, and the dry plots the smallest. But trees in frequently irrigated plots did not grow faster than in less irrigated plots where the soil was not reduced to the PWP.

Walnut trees did not respond in size to differential treatment as quickly as either the peach or prune trees. In fact, the trees in the dry treatment, which were the largest at the beginning of the experiment,
POOR IRRIGATION PRACTICES MAY RESULT IN

\section{SMALLER YIELD}

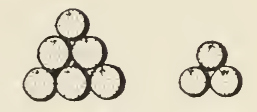

SMALLER FRUIT

POORER QUALITY

STUNTED TREES
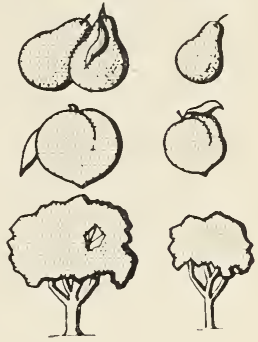

remained so for several years. This may be due to the deep-rooting habit and wide spacing of walnut trees.

Gains in size due to irrigation were comparatively slow in prune, peach, as well as walnut trees.

\section{Effect of Irrigation on Yield}

All plots of the prune orchards produced about equally before the various irrigation treatments were begun. A change in production started with the first year when the plots were irrigated according to project plan. The irrigated plots moved ahead of the unirrigated ones, and maintained their relative positions ever since. This change was due

The results reported here are summarized from long-time experiments with fruit trees at Davis, and from other experiments carried on for comparatively short periods in widely separated fruit-growing areas in California.

All experiments in the field were carried out in such a way that certain plots had readily available moisture at all times, while others were subjected to dry soil conditions after the moisture from winter rains was exhausted. In some cases intermediate treatments were also used. At Davis the irrigation treatments were greater in number, and each treatment was replicated several times. 
to the decrease in crop on the dry plots, rather than a marked increase in crops from the irrigated ones. The frequently irrigated plots did not produce more fruit, on the average, than the intermediate ones in which just enough irrigation was given to keep the soil moisture above the PWP.

The increasing differences in yields between the irrigated and the unirrigated treatments are due to the delayed effects of irrigation.

The yields of the intermediate plots indicate that some irrigation, while the crop is on the trees, is better than none at all, but this treatment is inferior to that where irrigation is frequent enough to provide readily available moisture at all times.

Similar results were obtained with peaches. The immediate effect of stopping irrigation during the growing season was a reduction in crop. This was largely due to a reduction in the size of the fruit which left a large percentage unmarketable. The intermediate plots (at PWP for short periods) fell behind the irrigated ones in production during the third summer of differential treatment.

\section{Relation of Tree Size to Yield}

Our experiments dealing with the irrigation of peach and prune trees confirmed observation in many places about a general relationship between tree size and yield. These results indicate that fruit trees grown in areas where irrigation is not possible are generally smaller and yield less than those in areas where irrigation water is applied when needed. These results also indicate the relatively slow yield response of trees to irrigation, particularly in areas similar to Davis where winter rainfall is ordinarily sufficient to provide water for a considerable portion of the growing season.

\section{Effect of Irrigation on Fruit Size}

Maintenance of readily available soil moisture allows the fruit to grow nor- mally according to the characteristic of the particular kind of fruit. Lack of readily available soil moisture while the fruit is growing causes an immediate check in growth. Slow growth of fruit on peach, pear, and prune trees has been repeatedly found at Davis when the soil moisture in the upper 5 or 6 feet of soil is reduced to the PWP. Similar results have been observed in the San Joaquin Valley on Japanese plums, on soils holding a comparatively small amount of available moisture.

In some areas, where winter rainfall is ample and the soil holds a comparatively large supply of moisture, certain early fruits may be grown to maturity without irrigation and reduction in fruit size, because the amount of moisture is sufficient to supply the needs of the tree at least until the crop is mature. Late fruits in these areas, however, show the characteristic responses to lack of moisture.

Almond and walnut fruits grow rapidly during the spring months and usually attain full size before the available soil moisture is exhausted. Reduction in sizes of almonds and walnuts is generally only noticeable in unirrigated areas following winters of exceptionally light rainfall.

Size of some kinds of fruits is also related to the numbers of fruits on the trees. If the fruits are not thinned, the final sizes may be unsatisfactory in spite of good irrigation. Of course, if the trees do not get sufficient water while the crop is growing, the fruits will be very small.

On soils holding comparatively large amounts of readily available moisture in the cool coastal regions, fruits may grow to normal size even though unirrigated.

In general, fruits may be expected to attain normal size, if the usual thinning practice is followed, and if the soil moisture does not remain at the PIVP while the fruits are growing.

Fruits stunted in growth because of he lack of moisture, begin to grow more rapidly than previously if the supply 
is replenished, but they always remain smaller than similar fruits not allowed to suffer for water.

\section{Effect of Irrigation in Soil with Readily Available Moisture}

If trees have readily available moisture, no measurable beneficial results are obtained by adding more water. In this case it does not follow that, if a little is good, more is better.

In our experiments neither the rate of growth nor yields were measurably increased in apple, peach, plum, prune and walnut orchards by irrigating while the soil moisture was above the PWP. No benefits, neither immediate nor delayed, were achieved by this treatment.

This finding once more confirmed that plants can take water readily from soil, no matter what its moisture content, as long as it is not reduced to the PWP. Transpiration will not decrease with decreasing soil moisture, growth will not be retarded, yields will not be lessened until PWP is reached. Neither will quality of the irrigated product deteriorate under these conditions.

\section{Water Intake by Trees Above the PWP-Scientific Considerations}

It is sometimes reasoned that because the resistance to removal of water from the soil by the plants increases as the soil-moisture content decreases, transpiration, growth, and other plant processes likewise must decrease. We believe this reasoning is incorrect.

Almost all of the water is taken by the plant from the soil and literally pulled through the plant, due to the different condition of the water within the leaves from that of the surrounding air.

The energy required to take water from the evaporating cells in the leaves is many times that needed to take water from the soil with its moisture at the PWP. Thus the relatively slight in- crease in energy requirements, as the soil moisture decreases, is ineffective in reducing water uptake by the plant. When the PWP is reached, however, there is a great increase in the tightness with which the water is held by the soil, and the plants will wilt. Failure to supply adequate water to the plant by the soil may not be due to an excessive amount of energy required to remove it from the soil at low moisture contents. There is the possibility that slow movement of water into the plant roots at low soil-moisture contents, or slow rate of root growth into moist soil, may be the cause of water deficiencies. Changes within the plant, if brought about by low soil moisture, may also affect water uptake by the plant.

Whether these things actually occur can only be determined by empirical trials. As stated before, our experiments with fruit trees have shown that their water needs can be supplied so long as the soil moisture is not reduced to the PWP in the soil occupied by the majority of the roots. It must be assumed, therefore, that such changes do not occur or that, if they do, their effects are not measurable until the soil moisture is reduced to the PWP.

Water is lost from the plant largely through openings in the leaves. These are called stomata and are capable of either closing or opening. Hence, it is reasoned that the condition of the stomata will affect transpiration. Considerable study has been given to them to find out whether the amount of readily available soil moisture influences their behavior. Our experiments show that stomata behave normally until the soil moisture is reduced to the PWP.

Photosynthesis does not decrease with decreasing soil moisture. Also, microbial activity in the soil is not reduced unless the PWP is reached.

The records of yields of fruit from 
trees in our experiments extending over many years also illustrate the fact that water is readily available between the field capacity and the PWP. The table shows some records from orchard plots on good deep soils with sufficient rain to wet the soil to a depth of from 6 to 9 feet each season.

Plots irrigated frequently kept the soil moisture at a relatively high level while the plots irrigated infrequently just had enough water to keep the soil moisture within the top 6 feet of soil from being at the PWP for an appreciable length of time. The differences in yield were not significant.

\section{The High Cost of Needless Irrigation}

Here is an example of the relative costs of growing prunes under frequent irrigation (with the intent of maintaining the soil moisture at a high level) as compared to infrequent irrigation which was just enough to keep the soil moisture from remaining at the PWP for more than 2 to 3 weeks during the growing season. For 13 years portions of a prune orchard were irrigated in this manner. The yield from the frequently irrigated portions was 46.9 tons of dried fruit per acre. The total cost of irrigation was $\$ 818.80$ for the 13-year period, and the income was $\$ 7,504$. The infrequently irrigated portions yielded 46.6 tons per acreat a cost of $\$ 579.60$ for irrigation, and an income of $\$ 7,456$.

\section{Local Conditions and Irrigation}

Ordinarily, soil moisture is readily available between the limits of field capacity and PWP. Yet, local conditions often will determine when to irrigate.

"Soil moisture," in this circular, means moisture in that part of the soil that is in contact with the absorbing portions of the roots. If the roots do not thoroughly penetrate the soil, there will be some parts of the soil that will not supply waier to the plant. Under such conditions, soil sampling will not give a true picture of the moisture conditions. Our observations of deciduous fruit trees and grape vines show that these plants have good root systems. There are, however, instances where the soil is too dense to permit root penetration.

Shallow soils, high water tables, alkali and high salinity also may be controlling factors in timing irrigations.

\section{Effects of Lack of Available Soil Moisture}

Lack of soil moisture during the growing season is almost always followed by immediate and harmful effects. The most

\begin{tabular}{|c|c|c|c|}
\hline Crop & $\begin{array}{l}\text { Number of } \\
\text { years in } \\
\text { experiments }\end{array}$ & Irrigations & $\begin{array}{l}\text { Cumulated yield } \\
\text { in pounds per tree }\end{array}$ \\
\hline Walnuts (hulled) & 23 & $\begin{array}{l}\text { Frequent } \\
\text { Infrequent }\end{array}$ & $\begin{array}{l}2,469.7 \\
2,498.8\end{array}$ \\
\hline Prunes (fresh fruit) & 19 & $\begin{array}{l}\text { Frequent } \\
\text { Infrequent }\end{array}$ & $\begin{array}{l}6,219.6 \\
6,046.4\end{array}$ \\
\hline Almonds (hulled) & 5 & $\begin{array}{l}\text { Frequent } \\
\text { Infrequent }\end{array}$ & $\begin{array}{l}105.35 \\
107.35\end{array}$ \\
\hline Apricots (fresh fruit) & 11 & $\begin{array}{l}\text { Frequent } \\
\text { Infrequent }\end{array}$ & $\begin{array}{l}1,966.9 \\
1,878.2\end{array}$ \\
\hline
\end{tabular}


common is a reduction in final size of fruits; this not only reduces the total yield, but materially reduces the amount of the marketable crop with those fruits that must meet a certain legal minimum size to be salable.

Lack of available moisture affects various fruits differently. Walnuts, for instance, growing rapidly during the early part of the season, ordinarily attain full size before the soil moisture from winter rains is exhausted. Lack of soil moisture later in the season, however, results in a larger proportion of blanks or partly filled shells. The weight-volume, or number of pounds of walnuts per cubic foot, of Concord Walnuts at Davis has been consistently lower in the dry plots during the past several years than in the irrigated ones.

These responses to lack of soil moisture during the growing season are fairly common. They occur year after year in many orchards, but are not cumulative in effect nor are they generally carried over from one year to the next.

If you have small fruit one year because you were unable to irrigate at the proper time, you may expect fruit of normal size the following season unless you again let the moisture become exhausted.

Yield losses and fruit-size reduction result if an irrigated orchard suddenly is deprived of water. This is not difficult to understand. The size of the aerial portion of the tree and the amount of crop set are largely determined by the treatment given the trees in previous years. The large leaf area, or large ground coverage by the trees, rapidly exhausts the available moisture. Unless the moisture is replenished the tree wilts, the fruits slow down in growth, and some of the new shoots may die.

These points were illustrated in experimental orchards at Davis. An entire orchard was given uniform treatment, including regular irrigation. All trees set a uniformly heavy crop. After a number of years certain plots were given a different irrigation. In some cases, the irrigation schedule was continued as before and continued to bear heavy crops. In other plots, irrigation was stopped. The trees in these dry plots exhausted the supply of moisture before the fruits attained full size. The result was a reduction of crop from the trees in these dry plots, and a reduction in the size of fruits.

In the prune orchards, for instance, the average yields were 290 pounds from the irrigated plots, and 172 pounds from the dry plots. The year before, the average yields on these same two groups of plots (but before differential treatment) had been 147 and 163 pounds. Fruit-size differences were even more marked: the irrigated plots produced an average of 21.6 per cent of large fruit; the dry plots only 2.7 per cent.

In the peach experiment the average yields of all the plots were substantially the same before differential treatment. The next year, irrigated plots averaged a yield of 232 pounds, dry plots 149 pounds. In addition to the yield loss, a large proportion of the crop from dry lots was unsalable because fruits did not reach the minimum size stipulated by the canneries.

\section{Effect of Irrigation on Fruit Quality}

It was believed that irrigation at certain periods of the growing season has an immediate and injurious effect on fruit quality. Our experiments have shown that this definitely is not the case. The highest quality is obtained when trees are supplied with moisture throughout the year.

Experiments with canning peaches showed that maintaining readily available moisture in the soil up to and including harvest time did not injure either the shipping or canning quality.

On the other hand, lack of moisture for several weeks before harvest produced peaches of tough, leathery texture.

Under similar conditions of dry soil, 
pears frequently have a high pressure test, indicating later maturity than those kept watered; but this difference in hardness tends to disappear in storage. Delay in maturity may be serious in districts where early shipping is desired.

Quality in prunes, as measured by the specific gravity, is apparently not greatly affected by the irrigation treatment. It seems to be associated with climatic conditions during the summer.

The drying ratios of prunes do not seem to be materially affected by the irrigation treatment. They are chiefly dependent on the amount of fruit on the trees. Years of large crops have high drying ratios while those of light crops have low ratios.

Cracking of prunes on the trees occurs from time to time to a serious extent. Experimental results and observations over many years indicate this trouble not to be due to irrigation; it probably has its origin in the climatic condition during the growing season.

\section{Benefits from Good Irrigation Practice}

The benefits derived from good irrigation practice are cumulative. Increased crops result chiefly from increased sizes of trees which in turn depend on the trees being kept healthy and vigorous. One of the chief factors in keeping trees vigorous is an irrigation plan providing readily available soil moisture at ALL times.

There appears to be no irrigation formula that will QUICKLY improve crops of deciduous fruits. Sometimes the benefits from irrigation may be slow in appearing, and are only apparent after several years.

On the other hand, immediate responses to changes in irrigation treatments result when the watering of trees is suspended. These responses are not only immediate, but they are often injurious.

\section{IRRIGATION DURING THE GROWING SEASON}

Assuming a mature orchard with the trees 24 feet apart on the square system, and with the majority of roots in the upper 5 feet of soil, there are 2,880 cubic feet of soil from which each tree may obtain water. This volume of soil is essentially a reservoir that contains, when it is filled to its field capacity, a definite amount of readily available moisture.

An example taken from actual measurements: a peach orchard in one of the largest peach-growing sections on clay loam soil with a field capacity of 25 per cent, two-thirds of which is readily available, contains approximately 260,000 pounds of dry soil in the 2,880 cubic feet. A 25 per cent moisture content of this soil is 65,000 pounds of water or 1,040 cubic feet. Two-thirds of this, or about 700 cubic feet of water, is readily available to the trees, and this quantity is equivalent to a depth of about 15 inches of water.

In other words, when the PWP is reached, an application of water 3 inches deep would be required to wet each foot of such soil.

Of course, if the entire 5 feet of soil is not reduced to the PWP, 15 inches will not be needed.

While an application of 15 acre-inches to the acre may seem too great when ordinary irrigations are considered, it must be remembered that ordinarily water is applied before all the readily available moisture is exhausted, or the soil is not wet to 5 feet.

Another experiment with clay loam soil showed it to have a field capacity of about 25 per cent, half of which was readily available. Only about 500 cubic feet of water could be used readily by the trees and it would require approximately $10 \frac{1}{2}$ inches of water to replenish the supply. 


\section{Use of Water by Trees During the Growing Season}

After the leaves are formed, the trees begin to draw upon the soil moisture and continue to do so until it is reduced to slightly beyond the PWP. After irrigating, this process is repeated. In practice, of course, the orchard should be irrigated before the trees wilt.

The number of times this cycle of events takes place during the growing season depends upon the size of the trees (the coverage of ground by the trees), the climatic conditions, and the kind and depth of the soil.

The total amount of water that comparable trees will use will not be greater on a clay soil than it is on a sandy soil if both are fertile and have readily available water at all times. Usually on sandy soils, however, water must be applied more frequently and in smaller amounts than on clay soils.

With the coming of warm weather, the readily available water is quickly used by the trees. It should be replenished.

\section{Weeds May Indicate Irrigation Needs}

You may be able to judge when your trees need water because of your close association with them and your daily observation of their condition.

When wilting or other evidences of lack of readily available moisture are hard to detect in the trees themselves, you may rely on some of the broadleaved weeds which may be left as indicator plants in various places in the orchard. Generally, such weeds are deeprooted enough to indicate by their wilting a lack of readily available water in the soil occupied by the roots of the trees.

The soil at this time will show, under examination, its condition of dryness, and the grower may become familiar enough with it to recognize when the moisture content is close to the PWP. At other times he may anticipate when this condition will be reached. This could avoid possible injury to the trees by actual wilting.

Where only small streams of water are available, the time necessary to cover the orchard may be so long that the trees which are irrigated last may be decidedly affected before they receive water. It is very important, therefore, to anticipate when the PWP will be reached so that irrigation may be started in time.

\section{Examples of Water Needs in California}

Here are some examples of water needs in various California fruit-growing areas, based on field experiments:

Mature peach trees in the Sacramento and San Joaquin valleys showed that the interval between depletions of the readily available moisture in the upper 5 feet of soil in the summer varied from 3 weeks in a sandy soil to 6 weeks in a clay loam soil.

On shallow, hardpan soils, trees should be irrigated more frequently with smaller applications of water than on deep soils.

Mature prune trees on loam soils in the Santa Clara Valley exhausted the readily available soil moisture in from 4 to 6 weeks during the hottest part of the season.

In the central coastal region, under low evaporating conditions, one irrigation during the growing season was sufficient for apple and pear trees on deep fine-textured soil.

Citrus on the coastal plain areas of San Diego County, in years of normal rainfall, need a summer irrigation of 12 to 15 acre-inches of water. The irrigation interval ranges from four weeks on the lighter soils to a maximum of six weeks on the heavier soils.

In the interior valleys of San Diego County and the intermediate areas of Orange County, the seasonal transpiration use by mature trees in good condition ranges from 18 to 22 acre-inches 
per acre. July and August are the months of heaviest use.

In San Bernardino County the use of water by a citrus grove with a heavy summer crop of weeds increased the seasonal use by 8 acre-inches of water per acre. In this orchard a maximum use of $71 / 2$ acre-inches per acre was observed during July which required irrigation at twoweek intervals.

Evergreen trees use water later in the fall and earlier in the spring than deciduous trees. They even use some moisture on clear warm days during the winter.

\section{Depth of Roots}

In most of our experiments, the distribution of roots of deciduous trees has been such that a uniform use of water has occurred in the top 5 to 6 feet of soil.

Studies in the irrigation of citrus groves show that an average of not more than 5 per cent of the moisture used was taken from the fifth foot of soil, which indicates that most of the roots were above this depth. In fact, in soils less than 3 feet in depth 50 to 60 per cent of the roots probably are in the first foot of soil or below the cultivated layer.

On the other hand, walnut trees on a fairly uniform soil extracted the moisture to a depth of 12 feet or more.

\section{Influence of Water Tables}

The presence of a high water table may, in some cases, result in upward movement rapid enough to replenish

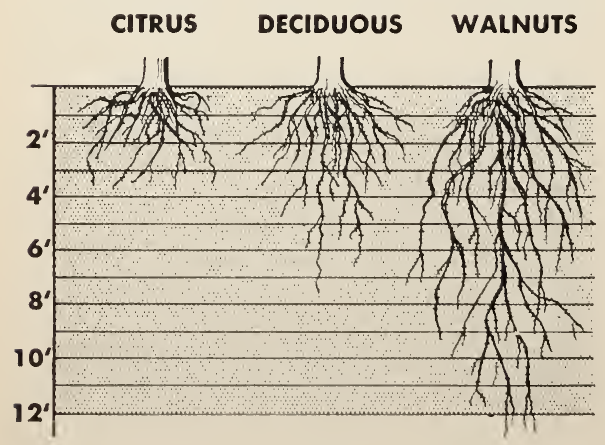

water in the upper layers. In others, the upward movement may not be sufficient to take care of the needs of the trees. Thus, it has been observed in some cases that frequent surface irrigations are necessary on certain types of soil even when the water table is fairly close to the surface.

Marked fluctuation of the water table during the growing season may produce harmful results. Under these conditions, a high water table should not be relied upon to supply moisture during the growing season, and drainage may be necessary. In addition harmful concentration of salts may accumulate if the water table is near the surface.

\section{Use of Cover Crops}

Cover crops in the orchard during the growing season do not conserve soil moisture.

The combination of trees and cover crops needs more water during the growing season than trees alone if the trees do not completely cover the ground.

The reduction of evaporation losses due to shading the soil by the cover crop is negligible when compared with the amount used by the plants. Furthermore, lessened transpiration by the trees because of the increased relative humidity brought about by cover crop transpiration is very slight.

Experiments with alfalfa in a mature peach orchard on a sandy soil indicate that the orchard needed about 50 per cent more water for the season with cover crops than without them. The increase in water use by the cover crop occurred in the spring and fall when the trees were defoliated.

\section{Maintenance of Readily Available Water}

The moisture content in the soil during the growing season ordinarily fluctuates between the field capacity and the PIVP.

If the soil-moisture content goes above the field capacity and remains there for 
any great length of time, the trees may be seriously affected. In several experiments, however, prune trees were kept with standing water around them for relatively long periods, with apparently no serious effects. Other trees, such as pears on French root, have been known to withstand saturated soils for long periods without apparent injury; but it is safer to avoid this condition.

Both the leaves and the fruit are affected when the soil moisture is reduced to the PWP. Fruit on trees on dry soil grows more slowly than fruit on trees having readily available moisture. It is exceedingly important, therefore, to see that the soil-moisture content does not remain at or go below the PWP for more than a few days.

The trees will not be affected, however, if the soil is irrigated when it already contains readily available water.

If possible, wet the soil at each irrigation to the depth in which most of the roots lie even though the lower layers still contain some readily available moisture. It is less expensive to wet this depth at this time than later.

Wetting the soil to a depth of 5 or 6 feet will usually be sufficient with most deciduous trees, and to a shallower depth with citrus trees. If there is an impervious layer within the depth mentioned, use just enough water to wet the soil above this layer.

"Overirrigation" is a term often used to mean frequent irrigation resulting in the maintenance of readily available moisture at a high level. Actually, overirrigation results when enough water is used on deep soils to cause percolation below the roots, or waterlogging.

Leaching may take place if irrigations are too frequent or too great in amount. Leaching may be necessary where the salinity of the soil is high and must be kept in balance.

The amount of water to be used at each irrigation varies with the kind and depth of soil to be wetted, and with its mois- ture content at the time of irrigation. If water is applied before the soil moisture content has reached the PWP, less water will be required to wet a certain depth.

The apparently deeper penetration of water obtained in some early irrigations over later ones is due to irrigation before all the readily available moisture is exhausted.

\section{SEASONAL IRRIGATION}

Spring. In some cases, irrigation during the spring is desirable.

If the winter rainfall has been insufficient to moisten the soil to a depth of 6 feet or more, this may be made up by spring irrigation. Again, if a cover crop has been allowed to grow so late that the readily available soil moisture is almost depleted, spring irrigation may be necessary. If a cover crop has not depleted the soil moisture, the first irrigation may be delayed until the readily available soil moisture is nearly exhausted, particularly, if only one irrigation can be given before the crop is harvested.

Fall. Many deciduous orchards in California are allowed to remain in a dry condition for a long period each fall.

As long as leaves remain on the trees and can function, some transpiration takes place if evaporation conditions are favorable.

Very often after the crop is picked, either no further water, or only one irrigation, is given. As a result, the trees may reduce the soil-moisture content to the $\mathrm{PWP}$, and then remain in a wilting condition for a long time. This affects some kinds of trees more than others. If it is necessary, however, to omit one irrigation from the regular schedule, the one in the fall may be eliminated with less danger of serious injury than one in midsummer.

Late-season irrigation. No evidence was found to support the belief that trees watered late in the season continue growing and do not mature their young growth and buds in time for them to 
withstand winter temperatures. No injury that could be attributed to lack of maturity has been produced in our experiments on prune, peach, or apricot trees, or on grapevines by watering late in the season.

With citrus fruits it is particularly important to maintain a supply of readily available water during the fall. In order to secure best results, trees should have readily available moisture in the fall as well as during the other seasons.

As a rule it is necessary to wet the soil in the fall only to a depth sufficient to supply the needs of the trees until rains begin. For example, if the orchard is irrigated late in September or October, only 2 or 3 feet of soil need be wetted.

Irrigation, also, is necessary for planting certain cover crops that seem to grow best when established early in the fall.

Winter. In some districts winter irrigation is practiced in deciduous orchards. This is unnecessary if the winter rainfall is sufficient to wet the soil to the depth containing most of the roots. If the rainfall has been insufficient for this purpose, irrigation during the winter is desirable. There must be readily available moisture present during the winter months even though the trees use little water at this time of the year.

Winter irrigation rests, in part, upon the desire to fill up the soil reservoir with cheap water for use in the growing season. As we have seen, the soil can only be filled to its field capacity and any additional water above that required to wet the soil occupied by the roots moves down, when drainage is unrestricted, and may be lost by deep percolation unless it is later recovered by pumping.
When drainage is restricted, however, winter irrigation may cause unfavorable soil-moisture conditions, because of the accumulation of free water above the hardpan, particularly in the low places in the orchard.

\section{INFLUENCE OF IRRIGATION ON ROOT DISTRIBUTION}

Our experiments also do not support the belief that, by withholding irrigation, trees may be made to send their roots deeply into the soil; that light irrigation tends to encourage shallow rooting; and that irrigating on one side of the tree only will result in confining the roots to that side. These ideas are not correct.

Our experiments show that if soils are wet only to a certain depth, and if the soil below this depth is at the PWP, the roots will be confined within the wetted area.

On the other hand, plants which are normally deep-rooted cannot be made to keep their roots in the upper layers of soil if those at lower depths have a readily available supply of moisture and if no other adverse condition for root development lies below.

If the soil is wet to the full depth to which the roots would normally go at the beginning of the growing season, then later applications of water during the summer will have no influence on the extent of the distribution of the roots, unless they be frequent enough to produce conditions that are unfavorable for root growth.

The presence of water in amounts above the field capacity, a condition often called waterlogging, may injure the roots of some trees. 


\section{CULTIVATION OF ORCHARDS}

\section{Losses of Moisture from Soils}

Does soil cultivation (to form a soil mulch) save moisture? Our experiments, as well as those of others, on the losses of water from soil, and the effect of cultivation on these losses, very clearly show that cultivation of itself does not conserve moisture.

The losses of moisture stored in the soil are caused by extraction by the roots of trees and other plants in the orchard, and by evaporation directly from the soil surface. Experiments show that the amount of water used in transpiration comprises a major portion of the total losses from the soil under California conditions.

A study of uncropped soils, both cultivated and uncultivated, in tanks and in field plots, showed that tillage of the soil did not save water. The soil dried out to the same extent and depth whether cultivated or not. It was also found that about half of the moisture that was lost within 80 days after the application of water was lost within the first week. This means that, even if cultivation did reduce evaporation, it would not be effective because so large a portion of the loss occurs before the surface soil is dry enough to be properly cultivated.

\section{Moisture Losses by Evaporation}

The loss of moisture by evaporation during periods longer than those usual between irrigations was confined to relatively shallow depths of soil, because the movement of moisture by capillarity from moist to drier soil is extremely slow in rate as well as slight in extent. A large portion of the loss was in the upper 4 inches. A much smaller amount was lost from the next 4 inches. Moisture below these upper 8 inches of soil was lost at an extremely slow rate.
In California where water is applied in such amounts that considerable depths of soil are wetted, the loss by evaporation from the surface layers is a small portion of the total.

Where a water table is relatively close to the surface, evaporation losses may be greater than those indicated.

\section{Cracking in Soils}

These experiments were made on different soils, including clays which cracked badly on drying when crops were grown on them, but which cracked only to very shallow depths when kept bare. Cracking is the result of drying, which in turn is brought about mostly by the extraction of water by plants. In most soils, cracking does not take place until the moisture content is reduced below the field capacity. In a few others, principally adobe soils, cracking may start before the soil is drained to its field capacity. In this case, cracking occurs while the soil is still too wet to be cultivated safely.

The loss of water by evaporation from the small cracks in the soil takes place at such a slow rate that probably nothing would be gained by covering them.

With large cracks, however, which form before the readily available moisture is exhausted, some water may be saved by the mulch where it is possible to cultivate the soil without puddling.

\section{Cultivation and Water Distribution}

The studies showed that cultivation had no influence on the distribution of water in the soil.

We found no evidence that stirring the surface soil influenced the upward movement of water. The part cultivation has been supposed to play in preventing the upward rise of moisture is based upon the theory that moisture can move in the 

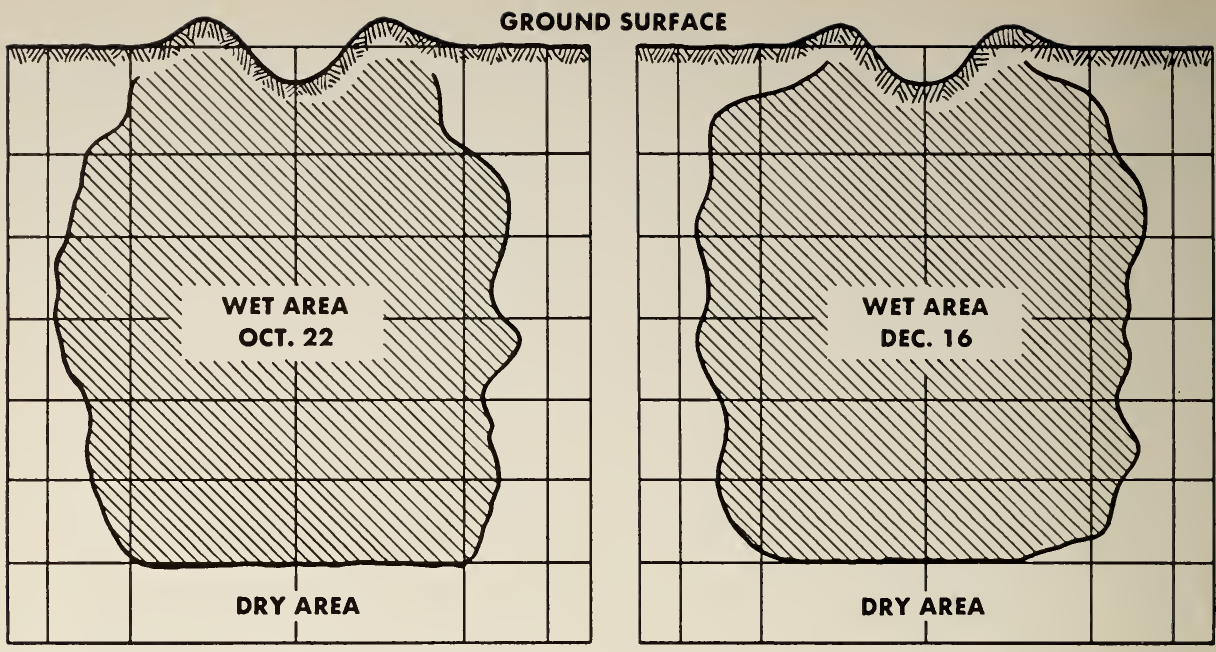

Water does not move rapidly either upward, sideways, or downward by capillarity, and it will stay until removed by plants. This graph is taken from actual measurements in an irrigation furrow. The soil is loam. After the water disappeared from the irrigation furrow, a trench was cut across it and the line of demarcation between moist and dry soil was noted. The trench was then covered. Fifty-six days later, it was opened, a new face was cut, and the line of demarcation was again determined, but the moisture movement was too slight to measure.

soil in all directions through capillarity and that by cultivation the upward movement is lessened. The loose dry soil is assumed to act as a blanket, shutting off evaporation. The loosening of the soil reduces the number of points of contact between the particles, and is supposed to lessen the capillary pulling power.

Since evaporation losses are confined so largely to a shallow surface layer, and since movement by capillarity is extremely slow, especially when the soil is not in contact with free water, movement of moisture from a lower depth does not take place rapidly enough to replace that lost by evaporation.

\section{Cultivation and Yield}

Numerous experiments have been made to measure the effectiveness of cultivation by means of yields produced. Results of many of these experiments are valueless. They contain too many varying factors. But where cause and effect can be segregated, the increased yields result- ing from cultivation can be attributed to the removal of weed competition.

\section{Deep Tillage}

Deep tillage (subsoiling, deep plowing, subsoil dynamiting) has been found ineffective to materially increase crop yields.

An added objection to deep tillage in orchards is the probable injury owing to root pruning.

On the other hand, subsoiling or blasting before planting may be desirable under special conditions where particular kinds of hardpan are present. These exist when the hardpan may be broken up economically by these methods, and it will not resume its original impervious condition upon being wetted again, and where the soil is pervious and fertile below.

\section{Cultivation and Soil Aeration}

There is abundant evidence that tillage, of itself, does not increase yields. Therefore, the idea that cultivation is 
beneficial for soil aeration and results in increased fertility and yields does not seem justified.

Experiments indicate that sufficient aeration ordinarily takes place in orchard soils.

Experiments in California have shown that rapid nitrification takes place below the depths affected by tillage.

On the other hand, unfavorable conditions for aeration result if water is applied frequently enough to fill the pore space in the soil and maintain this saturated condition too long.

Experiments of others show that crop yields are not increased by stirring the surface of the soil, and that cultivation does not increase aeration in the soil occupied by the roots of the trees.

Frequent cultivations may change the soil structure so that infiltration of water is retarded.

\section{The Purposes of Orchard Cultivation}

Cultivation in orchards should be directed toward certain useful purposes. Some of these are to:

1. Remove noxious weeds and weed competition.

2. Facilitate subsequent orchard operation, such as irrigation, harvesting, brush removal, and spraying.

3. Incorporate cover crops and manure.

4. Prepare the soil as a seed bed for cover crops.

5. Facilitate the control of certain pests.

6. Aid in the absorption of water where tillage or other orchard operations have produced an impervious condition of the soil.

Weeds, during the growing season, and cover crops, if allowed to grow too late in the spring, are serious competitors with the trees for moisture and nutrients. Cultivation is the best means of removing this competition.

Several orchards operations are greatly facilitated by having the soil in proper condition.
Better levees or furrows can be made when there is sufficient loose, dry soil on the surface than where the surface is hard or cloddy.

Picking of such crops as prunes and almonds is much easier from a loose, fine surface than from among clods or weeds.

Spraying and brush removal are made easier when irrigation levees are smoothed down and furrows filled up.

On steep slopes contour cultivation may stop water from running off and being wasted.

\section{Plow Sole}

Plow sole is a more or less impervious, dense layer of soil formed just below the depth of tillage.

Ordinarily, a plow sole will form if the soil is cultivated while too wet.

You can lessen the possibility of a plow sole forming if you limit the necessary cultivations to a time when the soil is in such a condition that it will not be puddled by the implement.

There is no accurate way to determine how dry a soil must be before it can be cultivated without forming a plow sole. Experience with each soil is your best guide.

Since cultivation, in the absence of weeds, has no influence in conserving moisture, much is to be gained by keeping off the ground until there is least danger of forming a plow sole.

Experience has shown that leaving the soil untilled is sometimes the best remedy in overcoming a plow sole.

\section{Repeated Cultivation and Soil Permeability}

Cultivation of a compacted surface layer may increase permeability of soil to water, but this lasts only for a very short time.

Repeated cultivation tends to decrease soil permeability. Keep all tillage operations in the orchard as shallow and as infrequent as necessary to accomplish the useful purposes mentioned. 


\section{Weed Control by Oil Sprays}

The use of oil sprays for controlling weeds has been followed in citrus orchards for a number of years, and to a limited extent in deciduous orchards.

Where this method has been used, growers report improved soil conditions. No harmful effects have been observed to date.

It should be remembered, however, that the oil-spray method has been used for only a relatively short period in deciduous orchards.

\section{Economy in Orchard Irrigation and Cultivation}

During the past several years, many California fruit growers have applied the principles set forth in this circular. In so doing they have materially changed previous practices in their orchards.

In general, cultivation has become less frequent and shallower. Furrows or levees are often used for two or more irrigations, instead of breaking them down and making new ones each time water is used.

The sides of levees used more than once may have to be cultivated lightly between irrigations. This is not to break down the levee, but to provide soil which fills the cracks in the levee resulting from drying. By following this procedure, levees may be used one or more times even on clay soils.

Because of the lessened number of cultivations there has been considerable saving in many cases in the cost of cultivation.

\section{A Rational Plan}

Disk the orchard in the spring, to eliminate weeds. Leave the soil with enough loose surface soil to construct furrows or levees later in the season. If it rains before the first irrigation, you may have to cultivate again. But do not till the soil merely for the sake of stirring it. Do not cultivate again until after the first irrigation unless the weeds are too numerous and large. In some cases, the orchard is cultivated after the first irrigation. In others, it is cultivated according to the amount of weed growth and cost of water.

You may leave the original furrows or levees for several irrigations if it costs less to replace the water used by weeds than it does to remove them. Follow the same general procedure with later irrigations; irrigate only when the readily available soil moisture is about exhausted.

Ordinarily cultivate and smooth the orchard before harvest to facilitate picking of crops such as prunes and almonds, and to avoid jolting fresh-fruit crops by hauling them over levees.

If you use tree props, cultivate the orchard early enough before harvest to permit the placing of the props.

Usually the soil in deciduous orchards is dry after harvest. Irrigation is then necessary. After the last irrigation do not cultivate unless

- a cover crop requiring seed-bed preparation is used

- it is necessary to break down the levees for spraying or removing pruning brush during the winter.

In all cases plan the irrigation schedule so that it does not interfere with spraying and harvesting operations.

IN CONCLUSION, and briefly stated, the most important purpose of cultivation of orchard soils is to remove weed competition.

The purpose of irrigation is to provide readily available moisture in the soil throughout the year. 